\title{
Bladder Cancer pT2a TNM Finding v6
}

National Cancer Institute

\section{Source}

National Cancer Institute. Bladder Cancer pT2a TNM Finding v6. NCI Thesaurus. Code C61211.

Bladder cancer with invasion into the superficial muscle layer. (from AJCC 6th Ed.) 